\title{
MEASURING DEVICE FOR OPTICAL PROPERTIES OF PLANT LEAVES
}

\author{
Sergey Rakutko, Elena Rakutko, Alexei Mishanov \\ Federal Scientific Agroengineering Centre VIM, Russia \\ sergej1964@yandex.ru
}

\begin{abstract}
Optical leaf properties serve as an important indicator of complex plant physiology under a broad range of environmental conditions. However, available relevant measuring instruments have several disadvantages. The study aimed to design a leaf photocolorimeter as a tool for a further comprehensive assessment of the impact of environmental factors on plants and optimisation of artificial plant lighting. The technical objective was to make this device user-friendly and improve its functional and ergonomic characteristics. The device had the following parts: the RGB LED block of BL-L515RGBC-CD type with the radiation peaks at $430 \mathrm{~nm}$ (blue), $525 \mathrm{~nm}$ (green) and $630 \mathrm{~nm}$ (red); a photodetector; a processor with Arduino UNO Rev3 board; LCD display; a keyboard; a power supply unit; a clamp; a thickness sensor; a lever; and a secure digital memory card. The measured leaf thickness, transmittances and optical density in spectral ranges, as well as the measurement time and sample identification record, formed a row in the database stored in the device's memory. Variation in the pigment content in cherry leaves, optical characteristics of plant leaves grown under natural conditions, and optical characteristics of tomato leaves under artificial lighting were measured in a set of experiments. The use of the device in the experiments provided for objective estimation of the plant leaf ageing process by the content of various pigments in the leaves. For this purpose, the specific optical density needed to be measured. The process estimation by leaf optical properties had a lower data variance and was more reliable than estimation by other biometric parameters. The designed device tests proved its wide capabilities in the rapid assessment of the growing plant status. Its practical application in greenhouse horticulture can help improve crop performance and yield quality.
\end{abstract}

Keywords: greenhouse horticulture, leaf, pigment, optical density.

\section{Introduction}

Investigation of the optical properties of plant tissues is an important task for understanding the plants' life cycle processes. Leaf optical properties reflect the three-dimensional structure and arrangement of leaf tissues, cells and organelles that determine the most important physiological processes of photosynthesis, respiration, and evaporation [1]. It is also of substantial interest to know the pigment content in the plant leaves as one of the most important diagnostic indicators of their status in greenhouse horticulture, which correlates with the biometric parameters. To date, the contribution of influencing factors to the variability of these indicators has not been estimated.

Investigation of leaf optical properties and light absorption mechanisms provides for understanding the general principles of solar energy assimilation, photosynthesis and adaptation processes in plants. Environmental conditions make the cell dimension, the morphology of assimilative tissues, the content and ratio of main pigments of photosynthesis - chlorophylls and carotenoids change; photosynthetic membranes organise differently - into sun-type chloroplasts and shade plant chloroplasts [2].

Environmental factors, both biotic and non-biotic, trigger a stress response in plants. The processes in the leaves in this case lead to the changes in leaf optical properties, by which the effect size may be determined. Optimisation of light environment is the most important task to address in greenhouse horticulture. For example, light environment parameters are of decisive importance to grow high-quality tomato transplants. They should be of the same size, have a straight, not elongated, thick stem, welldeveloped leaves and root system [3]. This ensures optimal development of plants after their transplanting and allows for an early, high-quality yield.

There are many optical methods for investigating plant organisms. For example, the transmittance or reflection coefficient of a quasi-monochromatic light beam may be a tool to estimate the leaf concentration of chlorophyll, carotenoids, and anthocyanins. More sophisticated methods can diagnose the functional status of plants by measuring the amplitude-phase characteristics of the quasimonochromatic radiation of the probe laser beam scattered on the plant tissue [4].

Convenient methods of non-destructive measurement of chlorophyll content by the light absorption by plant leaves were developed and tested on various crops: maize (Zea mays L.) [5], lentils (Lens culinaris Medik.) [6], sand pear (Pyrus serotina Rehd.) [7], maple sugar (Acer saccharum Marsh.) [8] and many others [9]. Several studies show that for individual plant species a calibration curve can be obtained linking the leaf optical properties and the absolute content of chlorophyll in the leaves [10]. 
The effect of light quality of radiation on light absorption by plant leaves during their development was revealed. So, the analysis of the absorption spectrum of a plant leaf may be suggested as one of the photo monitoring options [11]. Investigation of optical properties of objects is supported by the designed optical devices, which form the basis for new technologies to address the scientific and applied problems in ecology, geology and agriculture [12].

There are commercially manufactured devices available on the market. Yet many researchers prefer to design and manufacture them on their own, for example, a low-cost, low-tech colorimeter with an interchangeable LED [13]; a more advanced LED-based spectrometer with a total of seven wavelength selections [14]; spectrophotometer [15] and photocolorimeters of various design [16; 17] for educational purposes. The available measuring devices for the optical properties of solid objects, which include the plant leaves, have certain weak points. In the first place, they are not sufficiently functional and ergonomic, not quite convenient to be used directly in the cenosis. Some technical solutions require manual calibration; measurement results are not recorded in the internal memory or computer.

The study aimed to design a leaf photocolorimeter as a tool for measuring the optical properties of plant leaves for a comprehensive assessment of the impact of environmental factors and optimisation of greenhouse horticulture.

\section{Materials and methods}

The measurements were carried out in the laboratory of energy and ecology aspects of greenhouse horticulture of the Institute for Engineering and Environmental Problems in Agricultural Production (IEEP) - branch of FSAC VIM following previously developed methodology [18]. The optical characteristics of the leaves of selected plants grown under natural conditions in the experimental plot of the laboratory were measured in August 2019. The changes in the leaf optical properties under their ageing were studied using the example of cherry leaves in September 2019, when the leaves of different colour were found on the same tree at the same time. The leaf optical properties of plants grown under artificial lighting were measured on tomatoes (Solanum Lycopersicum L.) of the Blagovest F1 hybrid in February 2020. The seeds were sown in a seedling tray filled with a mixture of agro-peat and "Zhivaya Zemlya" substrate (Russia) in a 1:2 ratio. After the second true leaf appeared, the seedlings were pricked off into containers with the volume of one litre and placed in the room with an artificial climate, where they were grown until the age of 39 days from germination.

During the cultivation period, the containers with plants were randomly rotated and moved daily to minimise the effect of location within the rack. As the plants grew and developed, the relevant analyses were performed and, following visual observations, the missing mineral nutrients in the soil were supplied by foliar application. The air temperature was automatically maintained at $21 \pm 1.0^{\circ} \mathrm{C}$, the humidity - at $65-70 \%$. The air velocity in the plant growing zone was $0.2-0.3 \mathrm{~ms}^{-1}$.

Two lighting installations were used in the experiment, with OSRAM fluorescent lamps being the light source. In one installation, the share of blue radiation in the spectrum $(S p 1)$ was $10 \%$ higher than in the other installation ( $S p 2$ ) owing to several LEDs added.

The optical density of the leaves was analysed in the four-factor ANOVA model for different photoperiods $(P P)$ in two options - 16 and $12 \mathrm{~h}$, spectrum $(S p)$ in two options $-S p 1$ and $S p 2$, irradiance $(E)$ in three options $-100,170$, and $240 \mu \mathrm{mol} \mathrm{m}^{-1} \mathrm{~s}^{-1}$, and three leaf rows $(L)$, lower - Low, middle Medium, and upper - High. Additionally, the chlorophyll content in the leaves was recorded with CCM-200 device. The variance was analysed for the measured and calculated leaf optical properties: optical leaf density in the spectral ranges $D_{R}, D_{G}, D_{B}$; their specific values $D_{R}{ }^{s}, D_{G}{ }^{s}, D_{B}{ }^{s}$; the ratios $D_{R} / D_{B}$ and $D_{R} / D_{G}$, and the chlorophyll content $C C I$.

The values of transmittance $T_{i}, \%$, for each spectral range were calculated by the formula

$$
T_{i}=\frac{F_{i}}{F_{0 i}} 100,
$$

where $F_{0 i}$ and $F_{i}$ are, respectively, the incident flux and the flux passed through the measured sample in the $i$-th range. 
Optical density, $D_{i}$, dB, was calculated by the formula

$$
D_{i}=10 \log _{10}\left(\frac{1}{T_{i}}\right) \text {. }
$$

Specific optical density, $D_{i}^{s}$, dB $\cdot \mathrm{mm}^{-1}$, was calculated by the formula

$$
D_{i}^{s}=\frac{D_{i}}{d}
$$

where $d$-leaf thickness, mm.

The measurements had three to five replications. We checked the relevance of main assumptions that justify the use of variance analysis: the normality of distribution by gradation of factors by the Shapiro-Wilk test and the homogeneity of variances using the Cochran's Q test, Hartley's test, and Bartlett's test. The effect size (Strength of Association) $\eta^{2}$ was found as the ratio of factorial variance to the total variance. The data were analysed by methods of mathematical statistics $(p<0.05)$ using the Excel 2003 and Statistica 6.0 software packages.

\section{Design and circuit solutions of the device}

The designed and manufactured device was based on the previously created test installation for measuring the leaf optical density [19]. The test installation included an integrating sphere. Later it was found possible to avoid its use to improve the ergonomic properties of the device. Fig. 1 and Fig. 2 show the design and functional diagram of the leaf photocolorimeter.

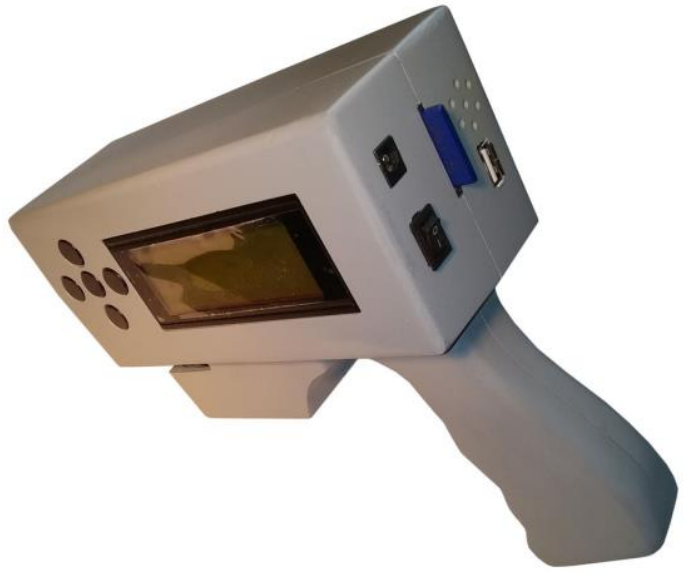

Fig. 1. Leaf photocolorimeter

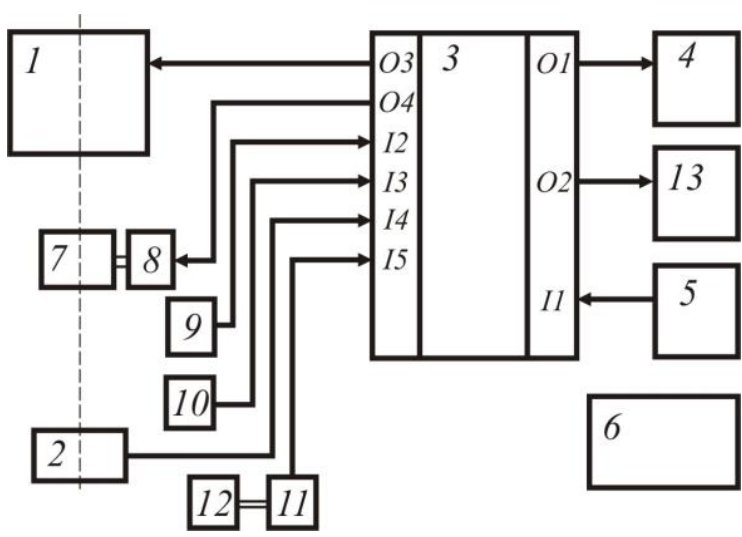

Fig. 2. Functional diagram of the leaf photocolorimeter

The device includes a block of LEDs 1 emitting in blue $B(400 \ldots 500 \mathrm{~nm})$, green $G(500 \ldots 600 \mathrm{~nm})$ and red $R(600 \ldots 700 \mathrm{~nm})$ ranges; photodetector 2; processor 3; display 4; keyboard 5; power unit 6; clamp 7; electromagnetic clamp drive 8; thickness sensor 9; clamp sensor 10; switch 11; lever 12 and memory unit 13. The device is made in the form of a pistol with all the elements inside. It has a slot for the measured sample (plant leaf) in its front part. The input $1(I 1)$ of processor 3 is connected to the output of the keyboard 5; the output $1(O 1)$ of the processor is connected to the input of the display 4 . The memory block 13 is connected to the output $2(O 2)$ of the processor 3 . Inputs $2(I 2), 3(I 3), 4(I 4)$ and 5 (I5) of the processor 3 are connected, respectively, with the outputs of the thickness 9 , clamp 10 , photodetector 2, and the switch 11 sensors. Output $3(O 3)$ of the processor 3 is connected to the input of LED block 1. Clamp 7 is mechanically connected to the electromagnetic drive 8 , the input of which is connected to the output $4(\mathrm{O} 4)$ of the processor 3. The spring-loaded lever arm 12 is rotatable about a fixed rotation axis and rests on the switch 11 .

The device works as follows. Before measurements the device is calibrated by setting the appropriate operating mode of the processor 3 using the keyboard 5. At that time there is no sample to measure in the body slot. The operator presses the lever 12, which rotates around its rotation axis and presses the switch 11, which is triggered and a signal is sent to the input 5 (I5) of the processor 3 . After 
that, a signal is sent from the output $4(\mathrm{O} 4)$ of the processor 3 to the electromagnetic drive 8 of the clamp 7. Then, after required time delays to stabilise the data readings, the processor generates signals, which go to the input of the LEDs block 1, providing alternate switching of LEDs of different spectral range found in this block. Radiation fluxes are measured by the photodetector 2 and are delivered as analog signals to the input 4 (I4) of the processor 3, where they are converted into digital signals. The values of flows $F_{0 i}$ from the $i$-th LED are stored in RAM of the processor 3. After releasing the lever 12, the clamp 7 returns to its original place and the device switches to the measurement mode.

The leaf is placed in the body slot and the lever 12 is pressed. Clamp 7 fixes the position of the sample being measured in the body slot, regardless of its thickness. At a given pressure of the clamp 7, the clamp sensor 10 is triggered, and the signal is read from the thickness sensor 9 through the input 2 (I2) of the processor 3, which stores the thickness value $d$ in the memory unit 13 . Then, as in the calibration mode, the LEDs in the block 1 are switched on one by one. The flows $F_{i}$ having passed through the sample are measured by the photodetector 2 and transmitted to the processor 3 , where the values of the transmittance, optical density and specific optical density are calculated for each spectral range by formulas (1-3). The values of $d, T_{i}, D_{i}$, and $D_{i}^{s}$ together with the measurement time and sample identification record form a row in the database recorded in the memory unit 13.

The processor in the device is the Arduino UNO Rev3 platform. The platform has digital inputs/outputs and analog-to-digital converters. The device is supplied with a SD Memory card. The keyboard of the device has separate click buttons; the display of the device is made on an LCD module; the LED block is made on an RGB LED of BL-L515RGBC-CD type, the radiation peaks of which are at $430 \mathrm{~nm}$ (blue), $525 \mathrm{~nm}$ (green) and $630 \mathrm{~nm}$ (red). A photo-resistor was taken as a photodetector.

\section{Test results and discussion}

Experiment 1. The device was used to determine the spectral transmittance coefficients $T$, $\%$, of cherry leaves. Table 1 shows the mean values of the coefficients and standard deviations. The measurements took place in the autumn, when the leaf pigmentation changes owing to seasonal processes.

Table 1

\section{Spectral transmittances of cherry leaves}

\begin{tabular}{|l|c|c|c|c|}
\hline \multirow{2}{*}{ Leaf colour } & \multirow{2}{*}{$\begin{array}{c}\text { Leaf thickness, } \\
\boldsymbol{d}, \mathbf{~ m m}\end{array}$} & \multicolumn{3}{|c|}{ coefficients, \% } \\
\cline { 3 - 5 } & $0.27 \pm 0.05$ & Blue $T_{B}$ & Green $T_{G}$ & Red $T_{R}$ \\
\hline Green & $0.30 \pm 0.05$ & $3.11 \pm 0.02$ & $9.30 \pm 0.37$ & $4.14 \pm 0.20$ \\
\hline Red & $0.21 \pm 0.04$ & $5.43 \pm 0.13$ & $9.31 \pm 0.36$ & $49.08 \pm 2.56$ \\
\hline Yellow & & $40.72 \pm 1.62$ & $57.53 \pm 2.86$ \\
\hline
\end{tabular}

The experiment revealed that the transmittance values in green leaves in all spectral ranges were small - from 0.74 to $5.43 \%$. The red leaf was characterised by an increased transmittance in the red range $-49.08 \%$. The yellow leaf had an increased transmittance in the green $(40.72 \%)$ and red $(57.53 \%)$ ranges. The thickness of leaves of different colour did not differ significantly. The device in this experiment helped estimate the plant ageing process by the leaf optical density.

Experiment 2. The device was used to measure the leaf thickness $d, \mathrm{~mm}$, optical density $D, \mathrm{~dB}$, and specific optical density $D_{i}^{s}, \mathrm{~dB} \cdot \mathrm{mm}^{-1}$, in separate $i$-th spectral ranges in selected plant leaves. Table 2 shows the average measured values.

The experiment revealed that the leaf thickness of the investigated plants varied within a fairly wide range - from 0.17 to $0.49 \mathrm{~mm}$. The analysis of the measurement results showed that measuring only the optical density was not enough to determine the pigment concentration in plant leaves due to the different thickness of leaf blades. In this case, the specific optical density needed to be determined. For example, the maximum optical density in the blue range was observed in cabbage leaves $(2.68 \mathrm{~dB})$ of the investigated plants. However, the reason for this was the increased leaf thickness $(0.49 \mathrm{~mm})$. The maximum value of the specific optical density $D_{B}{ }^{s}$ in this range $\left(11.82 \mathrm{~dB} \cdot \mathrm{mm}^{-1}\right)$ was observed in strawberry leaves, which had the smallest thickness $(0.17 \mathrm{~mm})$. 
Optical properties of selected plant leaves

Table 2

\begin{tabular}{|c|c|c|c|c|c|c|c|}
\hline \multirow{3}{*}{ Plant } & \multirow{3}{*}{$\begin{array}{c}\text { Leaf } \\
\text { thickness, } \\
d, \mathbf{m m}\end{array}$} & \multicolumn{6}{|c|}{ Spectral optical density } \\
\hline & & \multicolumn{2}{|c|}{ Blue } & \multicolumn{2}{|c|}{ Green } & \multicolumn{2}{|c|}{ Red } \\
\hline & & $\begin{array}{l}D_{B}, \\
\text { dB }\end{array}$ & $\begin{array}{c}D_{B}{ }^{s}, \\
\mathrm{~dB} \cdot \mathbf{m m}^{-1}\end{array}$ & $\begin{array}{l}D_{G}, \\
\text { dB }\end{array}$ & $\begin{array}{c}D_{G}^{S}, \\
\mathrm{~dB} \cdot \mathrm{mm}^{-1}\end{array}$ & $\begin{array}{l}D_{R}, \\
\text { dB }\end{array}$ & $\begin{array}{c}D_{R}{ }^{s}, \\
\mathrm{~dB} \cdot \mathbf{m m}^{-1}\end{array}$ \\
\hline Strawberry & 0.17 & 2.01 & 11.82 & 0.85 & 5.00 & 1.19 & 7.00 \\
\hline Horse-radish & 0.23 & 2.12 & 9.22 & 0.77 & 3.35 & 1.11 & 4.83 \\
\hline Celery & 0.24 & 1.77 & 7.38 & 0.58 & 2.42 & 0.90 & 3.75 \\
\hline Topinambur & 0.27 & 1.88 & 6.96 & 0.79 & 2.93 & 1.08 & 4.00 \\
\hline Pumpkin & 0.28 & 2.39 & 8.54 & 0.81 & 2.89 & 1.21 & 4.32 \\
\hline Tomato & 0.29 & 2.51 & 8.66 & 0.88 & 3.03 & 1.31 & 4.52 \\
\hline Potato & 0.32 & 2.17 & 6.78 & 0.79 & 2.47 & 1.09 & 3.41 \\
\hline Pepper & 0.33 & 2.36 & 7.15 & 0.74 & 2.24 & 1.06 & 3.21 \\
\hline Zucchini & 0.41 & 2.04 & 4.98 & 0.85 & 2.07 & 1.20 & 2.93 \\
\hline Cucumber & 0.41 & 2.40 & 5.85 & 0.88 & 2.15 & 1.16 & 2.83 \\
\hline Red beet & 0.44 & 2.62 & 5.95 & 1.37 & 3.11 & 1.23 & 2.80 \\
\hline Cabbage & 0.49 & 2.68 & 5.47 & 0.96 & 1.96 & 1.38 & 2.82 \\
\hline
\end{tabular}

Experiment 3. Table 3 summarises the results of determining the effect size (Strength of Association) $\eta^{2}$ of the light environment and the leaves' row on the leaf optical properties of tomato seedlings and the coefficients of variation of these parameters. Statistical analysis revealed significant differences in the variability of optical indicators and their sensitivity to the light environment factors.

Effect size of light environment factors on leaf optical properties

Table 3

and their coefficient of variation

\begin{tabular}{|c|c|c|c|c|c|}
\hline \multirow{2}{*}{ Parameter } & \multicolumn{4}{|c|}{ Effect size (Strength of Association) $\boldsymbol{\eta}^{\mathbf{2}}$} & \multirow{2}{*}{$\boldsymbol{K}_{\text {var }}$} \\
\cline { 2 - 5 } & $\{\mathbf{1}\} \boldsymbol{P P}$ & $\{\mathbf{2}\} \boldsymbol{S p}$ & $\{\mathbf{3}\} \boldsymbol{E}$ & $\{\mathbf{4}\} \mathbf{L}$ & 11.6 \\
\hline$C C I$ & 15.1 & - & 68.0 & 5.7 & 5.2 \\
\hline$D_{R}$ & 6.1 & - & 78.7 & 8.7 & 4.9 \\
\hline$D_{G}$ & 1.1 & - & 86.3 & 6.9 & 3.8 \\
\hline$D_{B}$ & - & - & $89.8^{*}$ & 5.2 & 10.2 \\
\hline$D_{R}{ }^{s}$ & 16.8 & - & 58.0 & 85.1 & 9.9 \\
\hline$D_{G}{ }^{s}$ & 13.3 & - & 27.2 & 46.3 & 10.5 \\
\hline$D_{B}{ }^{s}$ & 10.7 & - & 38.6 & 39.0 & 3.1 \\
\hline$D_{R} / D_{B}$ & 29.7 & 19.5 & 12.4 & 12.0 & $2.5^{* *}$ \\
\hline$D_{R} / D_{G}$ & 36.9 & - & 31.1 & - & \\
\hline
\end{tabular}

* Maximal effect size $* *$ Minimal coefficient of variation

When using the chlorophyll meter CCM-200, the average coefficient of variation of the measured $C C I(11.6 \%)$ was more than twice higher than that for the optical density values. This means that the chlorophyll content data obtained have a greater dispersion degree. Therefore, they are less reliable to assess the effect of light environment factors on plants. The experiment showed that to assess the effect of light environment factors on plants by the leaf optical density, there is no need to take into account the leaf thickness. Coefficients of variation of specific values of leaf optical density in the spectral ranges (9.9-10.5\%) turned out to be even higher than those of directly measured optical density $(3.8-5.2 \%)$.

The experiment revealed the difference in effect size of light environment factors on individual indicators of leaf optical properties. The biggest effect size observed was associated with irradiation estimated by the leaf optical density in the blue range (89.8\%). The light quality of radiation turned out to be the factor, which was the most difficult to detect in terms of the leaf optical properties response.

Of certain interest is the search for derived indicators from directly measured leaf optical properties that have the necessary statistical characteristics for individual practical cases. Thus, the ratio of leaf 
optical densities in red and green spectral ranges $D_{R} / D_{G}$ has the smallest coefficient of variation $(2.5 \%)$ out of the indicators considered in the study. The sensitivity of the ratio of leaf optical densities in red and blue spectral ranges $D_{R} / D_{G}$, in contrast to other considered indicators, turned out to be statistically significant for various radiation spectra. Therefore, this indicator may be used as a response to differences in the radiation spectrum of light sources.

\section{Conclusions}

The main technical result of developing a new device is its increased functionality, ease of use, and improved ergonomic performance. The leaf thickness sensor allowed to determine an additional parameter - specific optical density. The body design in the form of a pistol with a comfortable handle with a lever that controlled the clamping of the sample placed in the slot improved the ergonomic performance of the device during the measurements.

The device allows for optical density measurements at wavelengths of $430 \mathrm{~nm}, 525 \mathrm{~nm}$ and $630 \mathrm{~nm}$. In the experiment, the device helped reveal that with a cherry leaf ageing, the transmittance in the red range changed more intensively (one order of magnitude higher), while the changes in the blue and green ranges were much smaller. The sensitivity of the device in the whole range of measured optical densities was found sufficient to detect the difference in the leaves of certain plant species (from $0.58 \mathrm{~dB}$ for celery in the green range to $2.62 \mathrm{~dB}$ for red beets in the blue range). The software of the device allows testing various indicator calculation methods. This way it was found that the ratio of leaf optical densities in red and green spectral ranges had the smallest coefficient of variation $(2.5 \%)$ out of the indicators considered in the study.

\section{References}

[1] Jacquemoud S., Ustin S. Leaf Optical Properties. Cambridge: Cambridge University Press, 2019. doi:10.1017/9781108686457.

[2] Мерзляк М.Н. Спектры отражения листьев и плодов при нормальном развитии, старении и стресce (Reflectance spectra of leaves and fruits under normal development, aging and stress) Physiology of Plants: Физиология растений. 1997. Vol. 44. No. 5. pp. 707-716 (In Russian)

[3] Lee J.M., Kubota C., Tsao S.J., Bie Z., Hoyos Echevarria P., Morra L., Oda M. Current status of vegetable grafting: Diffusion, grafting techniques, automation. 2010. Sci. Hort. No. 127 pp. 93-105.

[4] Будаговский А., Будаговская О., Будаговский И. Парадоксы оптических свойств зеленых клеток и их практическое применение (Green cells paradoxes and their practical application). Photonics Russia: Фотоника. 2010. No. 6 (24). pp. 22-29 (In Russian)

[5] Shahryari R, Khayatnezhad M, Moghanlou B.S., Khaneghah A.M.P., Gholamin R. Response of maize genotypes to changes in chlorophyll content at presence of two types humic substances. Advances in Environmental Biology, 2011. No. 5(1). pp. 154-156.

[6] Ghassemi-Golezani K, Mahmoodi-Yengabad F. Physiological responses of lentil (Lens culinaris Medik.) to salinity. International Journal of Agriculture and Crop Sciences. 2012. No.4 (20) pp. 1531-1535.

[7] Ghasemi M, Arzani K, Yadollahi A, Ghasemi S, Sarikhani Khorrami S. Estimate of leaf chlorophyll and nitrogen content in Asian pear (Pyrus serotina Rehd.) by CCM-200. Notulae Scientia Biologicae. 2011. No. 3(1) pp. 91-94.

[8] Van den Berg A.K., Perkins T.D. Evaluation of a portable chlorophyll meter to estimate chlorophyll and nitrogen contents in sugar maple (Acer saccharum Marsh.) leaves. Forest Ecology and Management. 2004. No.200. pp. 113-117.

[9] Patane P., Vibhute A. Chlorophyll and nitrogen estimation techniques: a review. International Journal of Engineering Research and Reviews. 2014. Vol. 2, Issue 4, pp. 33-41.

[10] Alsina I., Dubova L., Erdberga I., Duma M., Avotinš A., Rakutko S. Comparison of lycopene and $\beta$-carotene content in tomatoes determined with chemical and non-destructive methods. Agronomy Research. 2019. vol. 17. No. 2. pp. 343-348.

[11]Кулешова Т.Э. и др. Влияние спектральных особенностей световой среды на поглощение света листьями салата и его нетто-продуктивность (The influence of the spectral properties of the lighting environment on light absorption by lettuce leaves and the net productivity of lettuce). Biofizika: Биофизика, 2020, vol 65, No. 1, pp. 112-124 (In Russian). 
[12] Кувалдин Э. В. Фотометры для измерения коэффициентов отражения природных объектов в спектральной области излучения солнца. (Solar spectral region photometers for natural objects reflectance measurements). Scientific Instrumentation: Научное приборостроение, 2005, vol. 15, No. 1, pp. 21-28 (In Russian).

[13] Gordon J., James A., Harman S., Weiss K. A Film Canister Colorimeter. Journal of Chemical Education, vol. 79(8), 2002, pp.1005-1006. DOI: 10.1021/ed079p1005

[14] Yeh T.-S., Tseng S.-S. A Low Cost LED Based Spectrometer. Journal of Chinese Chemical Society, vol.53(5), 2006, pp.1067-1072. DOI: 10.1002/jccs.200600142

[15] Thal M. A ., Samide M.J. Applied electronics: Construction of a Simple Spectrophotometer. Journal of Chemical Education, vol. 78(11), 2001, pp. 1510-1512. DOI: 10.1021/ed078p1510

[16] Rohit, Kanwar K., Rao K. Development of a low-cost portable Colorimeter for the estimation of fluoride in drinking water. Sensors and Actuators B: Chemical, vol. 149(1), 2010, pp. 245-251. DOI: 10.1016/j.snb.2010.05.021

[17] Navas D.R., Castro J., Rodriguez-Arias H.A. Design and Implementation of a Photocolorimeter Using Microcontrollers to Determine Analyzes in Aqueous Solutions. Proceedings of the 16th LACCEI International Multi-Conference for Engineering, Education, and Technology "Innovation in Education and Inclusion", 19-21 July 2018, Lima, Peru. (In Spainish) DOI:10.18687/LACCEI2018.1.1.170

[18] Ракутько Е.Н., Ракутько С.А. Методика измерения оптической плотности листьев растений с применением денситометра ДП-1М (Measurement technique of plant leave optical density with DP-1M densitometer). Technologies, machines and equipment for mechanised crop and livestock production: Технологии и технические средства механизированного производства продукции растениеводства и животноводства. 2018. No. 94. pp. 23-35 (In Russian).

[19] Rakutko S., Rakutko E., Avotins A., Apse-Apsitis P. Method and device for measuring stability of plant development by fluctuating asymmetry of optical density of leaves. Proceedings of 18th International Scientific Conference "Engineering for Rural Development". May 22-24, 2019. Jelgava, Latvia, pp. 1263-1268. 